\title{
Article \\ Chronic Gamma Irradiation Changes Phenotype and Gene Expression Partially Transmitted to Next-Generation Tomato Seedlings
}

\author{
Seong-Min Kim ${ }^{1,2,+}$, Yeong Deuk Jo ${ }^{3,+}{ }^{\circ}$, Jae-In Chun ${ }^{1,2}$, Jin-Baek Kim ${ }^{3}\left(\mathbb{D}\right.$ and Jin-Ho Kang ${ }^{1,2,4, * \mathbb{C}}$ \\ 1 Department of Agriculture, Forestry and Bioresources and Integrated Major in Global Smart Farm, \\ College of Agriculture and Life Sciences, Seoul National University, Seoul 08826, Korea; \\ poba7750@snu.ac.kr (S.-M.K.); janechun@snu.ac.kr (J.-I.C.) \\ 2 Institutes of Green-Bio Science and Technology, Seoul National University, Pyeongchang 25354, Korea \\ 3 Radiation Breeding Research Team, Advanced Radiation Technology Institute, \\ Korea Atomic Energy Research Institute, Jeongeup 56212, Korea; jyd@kaeri.re.kr (Y.D.J.); \\ jbkim74@kaeri.re.kr (J.-B.K.) \\ 4 Graduate School of International Agricultural Technology, Seoul National University, \\ Pyeongchang 25354, Korea \\ * Correspondence: kangjinho@snu.ac.kr; Tel.: +82-33-339-5831; Fax: +82-33-339-5825 \\ + These authors contributed equally to this work.
}

Citation: Kim, S.-M.; Jo, Y.D.; Chun, J.-I.; Kim, J.-B.; Kang, J.-H. Chronic Gamma Irradiation Changes Phenotype and Gene Expression Partially Transmitted to Next-Generation Tomato Seedlings. Agronomy 2021, 11, 1638. https:// doi.org/10.3390/agronomy11081638

Received: 6 July 2021

Accepted: 13 August 2021

Published: 17 August 2021

Publisher's Note: MDPI stays neutral with regard to jurisdictional claims in published maps and institutional affiliations.

Copyright: () 2021 by the authors. Licensee MDPI, Basel, Switzerland. This article is an open access article distributed under the terms and conditions of the Creative Commons Attribution (CC BY) license (https:// creativecommons.org/licenses/by/ $4.0 /)$

\begin{abstract}
Compared to the studies on acute irradiation of seeds, fewer studies have reported on the chronic irradiation of seedlings, especially in fruit-bearing vegetables. We examined the effects of chronic gamma irradiation on tomato (Solanum lycopersicum 'Micro-Tom') seedlings exposed to gamma rays $(50,100,150$, and $200 \mathrm{~Gy})$ for 4 weeks. As the total dose of gamma rays increased, leaf length, trichome density, and seed number were reduced in the irradiated seedlings $\left(\mathrm{M}_{1}\right)$. Additionally, a change in fruit shape was observed. Chronic gamma irradiation reduced the expression of two trichome-related genes and affected the expression levels of 11 reactive oxygen species (ROS)-related genes. We examined the transmittance of these effects using $\mathrm{M}_{2}$ plants. The trichome density and fruit shape were similar between $\mathrm{M}_{2}$ and control plants; however, a reduction in leaf length and seed number was detected in $\mathrm{M}_{2}$ plants. Interestingly, changes in the expression of four ROS-related genes (ZAT10, Mn-SOD, POD3, and RBOH1) found in $\mathrm{M}_{1}$ were detected in $\mathrm{M}_{2}$ plants. Thus, the changes in phenotype and gene expression induced by chronic gamma irradiation were transmitted to the next generation. Additionally, we found novel mutants from $\mathrm{M}_{2}$ plants, suggesting that chronic gamma irradiation may be considered in tomato mutation breeding.
\end{abstract}

Keywords: chronic gamma irradiation; fruit shape; mutation breeding; reactive oxygen species-related gene; tomato; trichome

\section{Introduction}

Irradiation of plant tissues causes various biological effects at both morphological and physiological levels of plant organisms and cellular levels [1]. At the morphological and physiological levels of plant organisms, the irradiation of rice with carbon beams or gamma rays results in morphological and functional defects, including reduction in fertility [2] and plant height [3]. Gamma irradiation also causes other developmental changes, such as increased trichome density in Arabidopsis [4] and elongation of internode diameter in Brachypodium [5]. At the cellular level, gamma rays alter the amount of sucrose in potato [6] and anthocyanin in wheat [7]. Furthermore, gamma irradiation causes damage to cell walls in Brachypodium [5] and alters the structure of mitochondria and chloroplasts in Arabidopsis [8]. Notably, irradiation significantly modifies genetic properties by causing DNA mutations [9], by introducing epigenetic modifications [10], and by altering gene expression [11]. Among these genetic properties, heritable changes can be considered 
for radiation mutation breeding, which is the best-known and the most widely applied radiation technology in plants [12].

A mutant population can be developed and established by irradiating seeds or plants to harbor random mutations. Individual lines containing useful and inheritable characteristics are selected in later generations and are used as breeding materials for the development of new cultivars. However, most phenotypic changes observed in irradiated plants $\left(\mathrm{M}_{1}\right.$ plants) are caused by physiological responses rather than heritable genetic changes [13]. Therefore, it is generally accepted that changes in certain characteristics found in $\mathrm{M}_{1}$ plants are mostly not detected in their progeny $\left(\mathrm{M}_{2}\right.$ plants) when mutagenesis is performed in seed-propagated plants with homozygous genomes [1]. In contrast, phenotypes due to inherited DNA mutations are rarely detected in $\mathrm{M}_{1}$ plants because recessive mutations account for most mutations [1]. For the transmission of DNA mutations, through the analysis of two successive generations of gamma-irradiated Arabidopsis, it was found that most DNA structural variations induced by irradiation were not transferred to the next generation. This was presumably because considerable DNA structural variations hamper the viability of gametes in the haploid state [14]. Regarding mutation efficiency, many factors such as radiation dose, linear energy transfer (LET) of radiation, irradiation conditions, and irradiated tissues affect the frequency and spectrum of mutations [15]. Yamaguchi et al. [16] have suggested that the dose corresponds to the shoulder (the dose at which the survival rate of plants begins to rapidly decrease) in the dose-survival rate curve, as the optimal dose to obtain the highest number of mutants per sown $\mathrm{M}_{1}$ seeds. Recent genomics studies have shown that high-LET radiation, pertaining to the application of heavy ion beams (e.g., argon and carbon ion beams) and fast neutrons, induces more marked and increasingly complex DNA structural variations, thus resulting in a higher frequency of gene mutations than those observed with low-LET radiation, such as gamma rays in Arabidopsis and rice [17-19]. The irradiation dose rate also affects the genomic characteristics. Acute irradiation, which is conducted at a relatively high dose rate in a short period (usually ranging from several hours to 1 day), has been widely used for conducting mutation breeding $[17,20,21]$. Recently, the impact of acute irradiation on DNA mutations was investigated through whole-genome sequencing analyses by subjecting Arabidopsis and rice to treatment with several radiation sources (e.g., fast neutrons, heavy ion beams, and gamma rays) [15]. However, chronic irradiation, characterized by a low dose rate over a relatively long period (ranging from several days to months) during plant development, has been less studied than its counterpart.

Treatment of plants with chronic irradiation requires special facilities for the growth of plants subjected to irradiation. For example, the gamma field in Japan [22], gamma phytotron in the Republic of Korea [23], and the gamma greenhouse in Malaysia [24] have demonstrated successful results pertaining to the treatment of plants with chronic irradiation. Several mutants with novel traits have been obtained through chronic irradiation, including a black spot disease-resistant pear variety ('Gold Nijisseiki') [25] and 10 chrysanthemum cultivars with variation in flower color and shape [26]. A few studies have shown that chronic irradiation subsequently induces physiological responses or inflicts damage, such as reduction in the fertility in rice [3], alterations in the expression patterns of diverse genes in Arabidopsis and wheat [7,11], and degradation of lignocellulose in Brachypodium [5]. Whole-genome sequencing of Arabidopsis lines that were chronically or acutely subjected to irradiation with gamma rays for five generations showed that chronic irradiation could generate a higher frequency of heritable DNA mutations than those observed with acute irradiation [17]. However, the heritability of various biological effects of chronic irradiation has not been examined in successive generations. When we consider the differences in dose rate and duration of irradiation between acute and chronic irradiation, the biological effects and their inheritance following subjection to chronic irradiation may differ from those following subjection to acute irradiation. Therefore, research is warranted to elucidate the specific effects of chronic irradiation exerted on plants and their progeny. 
Tomato (Solanum lycopersicum) is a vegetable crop that is cultivated globally with considerable production [27]. Additionally, as tomato is considered a model plant, assembly of a high-quality genome has been realized (Tomato Genome Consortium, 2012), and diverse plant materials, including mutant lines, have been developed for functional genomics studies and breeding [28-30]. In the development of mutant populations, the application of acute gamma irradiation or ethyl methanesulfonate (EMS) treatment has mainly been considered for mutagenesis. The frequency and spectrum of DNA mutations induced by gamma irradiation and EMS treatment were determined in mutant lines of dwarf tomato ('Micro-Tom') via whole-genome sequencing [31]. For chronic irradiation, the radiosensitivity of tomato has been reported in several studies [32,33]. However, research on the physiological and genetic effects of chronic irradiation in tomatoes remains limited.

In the present study, changes in the physiological characteristics and expression levels of genes related to radiation responses were investigated following the use of chronic gamma irradiation in tomatoes. Additionally, the inheritance of these characteristics was examined in the next generation. Our results provide essential information on the biological effects and inheritance patterns necessary for consideration of the application of chronic irradiation technology for the development of tomato genetic resources.

\section{Materials and Methods}

\subsection{Plant Growth and Gamma Irradiation Conditions}

Tomato 'Micro-Tom' (LA3911) seeds were sown in 72-hole seedling trays (Bumnong Co., Jeong-eup, Korea) with a soil mixture (Super-baroker, Seoul Bio Co., Eumseong, Korea) and subjected to growth in a greenhouse under natural light conditions for $16 / 8 \mathrm{~h}$ (light/dark) with daily and nightly temperature $26{ }^{\circ} \mathrm{C}$ and $20{ }^{\circ} \mathrm{C}$, respectively, and $60 \%$ relative humidity. After a period of two weeks, plants were individually transferred into $11 \mathrm{~cm}$-diameter pots. Three-week-old plants were moved to a gammaphytotron facility and maintained under conditions of photoperiod $16 / 8 \mathrm{~h}$ (light of intensity $250 \mu \mathrm{mol} \mathrm{m} \mathrm{m}^{-2} \mathrm{~s}^{-1}$ /darkness) with daily and nightly temperature $26^{\circ} \mathrm{C}$ and $20^{\circ} \mathrm{C}$, respectively, and relative humidity of $60 \%$ (Figure S1). Tomato seedlings were placed at different distances and irradiated with gamma-rays for 4 weeks at $50 \mathrm{~Gy}(74.4 \mathrm{mGray} / \mathrm{h}), 100 \mathrm{~Gy}$ (148.81 mGray/h), 150 Gy (223.21 mGray/h), and $200 \mathrm{~Gy}(297.62 \mathrm{mGray} / \mathrm{h})$ by using a ${ }^{60} \mathrm{Co}$ irradiator (20 TBq of capacity, Ottawa, ON, Canada) at the Korea Atomic Energy Research Institute (KAERI). For consideration of $0 \mathrm{~Gy}$ as a control, tomato seedlings were subjected to protection by using a lead wall to prevent gamma-ray exposure. The gamma-irradiated $\mathrm{M}_{1}$ seedlings were transferred to the greenhouse and cultivated under the same conditions as described above to harvest $M_{2}$ seeds. $M_{2}$ seeds were germinated in 72-hole seedling trays with a soil mixture and cultivated in the greenhouse under the same conditions mentioned above. After a period of two weeks, each $\mathrm{M}_{2}$ plant was transferred into $11 \mathrm{~cm}$-diameter pots and cultivated to harvest $\mathrm{M}_{3}$ seeds.

\subsection{Microscopic Observations and Trichome Counting}

A dissecting microscope (Leica CH-M205A, Wetzlar, Germany) equipped with LED5000 RL light sources (Leica) and a Leica MC170 HD camera was used to observe trichome morphology and to measure trichome density, as per methods previously described [34]. Seven-week-old $\mathrm{M}_{1}$ (4 weeks after gamma irradiation) and $\mathrm{M}_{2}$ plants were used. The primary leaflet of the second compound leaf underneath the shoot apical meristem was selected, and the adaxial leaf surfaces of the middle region of the leaflet were used for trichome counting (Figure S2).

\subsection{Total RNA Extraction and Quantitative Real-Time Polymerase Chain Reaction (qRT-PCR)}

The leaves of the control and gamma-irradiated plants were collected from the same region used for trichome observation. Total RNA isolation and cDNA synthesis were conducted using the TRIzol reagent (\#15596018, Invitrogen) and a cDNA synthesis kit (\#K1622, Thermo Fisher Scientific, Waltham, MA, USA). Genes involved in trichome development 
(Wo, CycB2, MYC1, and TPS5) or those related to reactive oxygen species (ROS) signaling and scavenging (HsfA4a, WRKY39, CML51, ZAT10, Mn-SOD, cAPX, GPX, ph-GPX, POD3, $C A T 1, C A T 3$, and $R B O H I)$ were selected for quantitative real-time polymerase chain reaction (qRT-PCR). ACT7 was selected as an internal standard. Primer sets for each gene are listed in Table S1. qRT-PCR was performed in $20-\mu \mathrm{L}$ reaction mixtures containing the cDNA template equivalent to $20 \mathrm{ng}$ of total RNA, $10 \mu \mathrm{M}$ of each primer, $10 \mu \mathrm{L}$ of Solg ${ }^{\mathrm{TM}}$ $2 \times$ real-time PCR smart mix, and $1 \mu \mathrm{L}$ of EvaGreen (\#SRH71-m40h, Solgent, Daejeon, Korea) using the AriaMx Real-time PCR system (G8830A, Agilent Technologies, Santa Clara, CA, USA). The PCR conditions included the following: $95^{\circ} \mathrm{C}$ for $15 \mathrm{~min}$, followed by 40 cycles at $95^{\circ} \mathrm{C}$ for $20 \mathrm{~s}$ and at $60{ }^{\circ} \mathrm{C}$ for $40 \mathrm{~s}$.

\section{Results}

3.1. Chronic Gamma Irradiation Reduces Plant Growth, Trichome Density and Seed Number, and Induces Abnormal Fruit Shape in Tomato

To investigate the effect of chronic gamma irradiation exerted on tomato plants, 3week-old tomato seedlings were irradiated with 50,100, 150, and 200 Gy of gamma rays for a period of 4 weeks (Figure S1). We then compared several phenotypes between the gamma-irradiated $\mathrm{M}_{1}$ plants and the control plants (0 Gy). First, the gamma-irradiated $\mathrm{M}_{1}$ plants showed different growth rates. The leaf length of plants irradiated with 50 and $100 \mathrm{~Gy}$ was similar to that of the control plants. However, the leaf length of plants irradiated with 150 and 200 Gy was reduced by $19.7 \%$ and $20.0 \%$, respectively, compared to that of the control plants (Figure 1A). In Arabidopsis and soybean, trichome density is altered by gamma irradiation $[4,35,36]$. Therefore, we measured the number of type I and VI trichomes (Figure S2), which are representative of tomato trichomes, to determine whether gamma irradiation also induced trichomes in tomato. As the total dose of gamma rays increased, the number of type I trichomes on the leaves gradually decreased. However, the number of trichomes between gamma-irradiated plants and control plants did not significantly differ (Figure 1B,C). The density of type VI trichomes on leaves also decreased when the intensity of gamma rays increased. The number of type VI trichomes on $50 \mathrm{~Gy}$-irradiated leaves slightly decreased by $12 \%$ compared to that on the control leaves. However, the number of type VI trichomes on $100 \mathrm{~Gy}-, 150 \mathrm{~Gy}-$, and $200 \mathrm{~Gy}$-irradiated leaves was significantly reduced by $25 \%, 33 \%$, and $59 \%$, respectively, compared to that on the control leaves (Figure 1B,D). These results indicated that chronic gamma irradiation negatively affected trichome density in tomatoes.

In addition to the trichome density changes, chronic gamma irradiation also affected the shape of the tomato fruit. As the total dose of gamma irradiation increased, gammairradiated plants exhibited the development of a peanut-shaped fruit with a higher lengthto-width ratio than that observed on control plants, which demonstrated a typical round shape (Figure 1E). In particular, the length-to-width ratio of $100 \mathrm{~Gy}$ - and $150 \mathrm{~Gy}$-irradiated fruits significantly increased to $21 \%$ and $31 \%$, respectively, compared with that of control fruits. In $200 \mathrm{~Gy}$-irradiated plants, fruit size was markedly smaller than that of control plants, which resulted in the achievement of a similar length-to-width ratio between $200 \mathrm{~Gy}-$ irradiated fruit and control fruit (Figure 1E,F). Chronic gamma irradiation also affected the seed set. The number of $\mathrm{M}_{2}$ seeds obtained from $50 \mathrm{~Gy}$ - and $100 \mathrm{~Gy}$-irradiated $\mathrm{M}_{1}$ plants slightly decreased to 7-19\%, but was not significantly different from that obtained from control plants. The number of $\mathrm{M}_{2}$ seeds obtained from $150 \mathrm{~Gy}$ - and $200 \mathrm{~Gy}$-irradiated $\mathrm{M}_{1}$ plants significantly decreased to $35 \%$ and $92 \%$, respectively, compared to that obtained from control plants. (Figure 1G). These results indicated that chronic gamma irradiation affected several aspects of growth and development in tomatoes. 
A

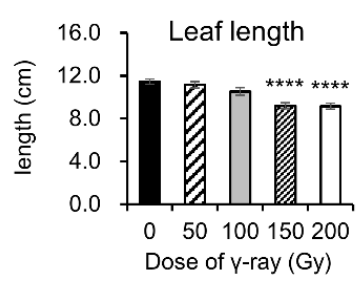

B

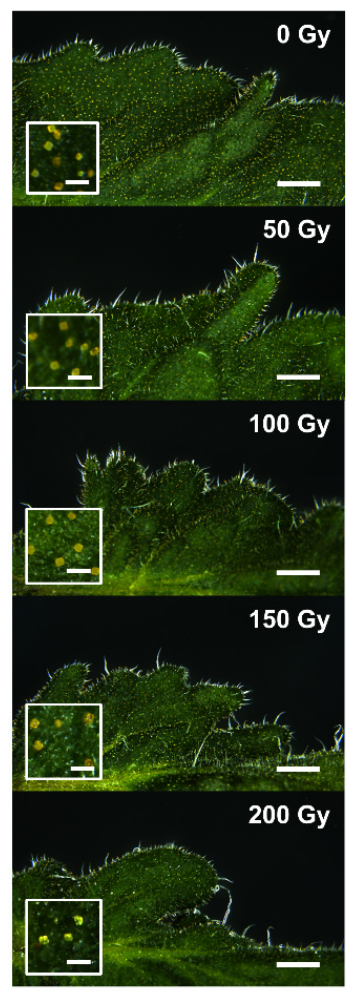

C

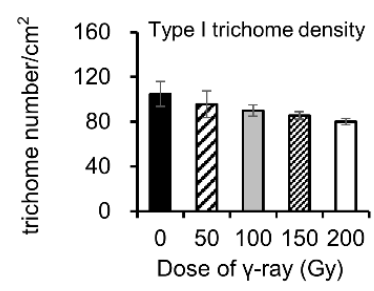

D
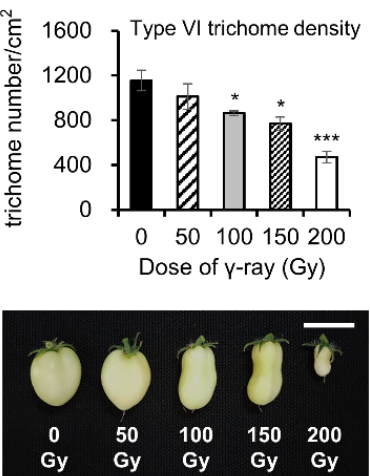

$\mathbf{F}$

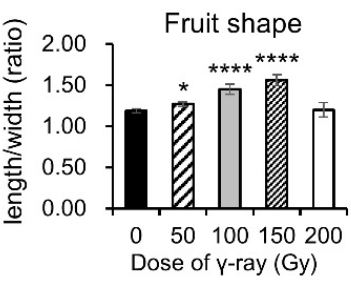

G

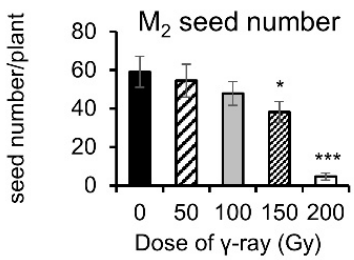

Figure 1. Effect of chronic gamma irradiation on growth and development of tomato $\mathrm{M}_{1}$ plants. Plants irradiated with 50, 100, 150, or 200 Gy of gamma rays for 4 weeks were compared with control (0 Gy) plants. (A) Leaf length of control and gamma-irradiated plants. The length from the center of the plant to the edge of the largest terminal leaflet was measured. Data are presented as mean $\pm \mathrm{SE}$ of 16 biological replicates for each dose. Asterisks represent significant differences between gammairradiated and control plants (unpaired $t$-test: ${ }^{* * * *} p<0.0001$ ). (B) Dissecting micrographs of the adaxial leaf surfaces of the control and gamma-irradiated plants. Scale bars represent $2 \mathrm{~mm}$. Insets show representative type VI trichomes, and scale bars in the insets indicate $0.2 \mathrm{~mm}$. (C,D) Density of type I (C) and VI (D) trichomes on the adaxial leaves of control and gamma-irradiated plants. Data are presented as mean $\pm \mathrm{SE}$ of four biological replicates for each dose. Asterisks represent significant differences between control and gamma-irradiated plants (unpaired $t$-test: ${ }^{*} p<0.05$; *** $p<0.001$ ). (E) Shape of mature green fruit in the control and gamma-irradiated plants. Scale bar indicates $2 \mathrm{~cm}$. (F) Length-to-width ratio of mature-green fruit in control and gamma-irradiated plants. Data are shown as mean $\pm \mathrm{SE}$ of 12 biological replicates. Asterisks represent significant differences between control and gamma-irradiated plants (unpaired $t$-test: ${ }^{*} p<0.05 ; * * * * p<0.001$ ). (G) $\mathrm{M}_{2}$ seed number in control and gamma-irradiated M1 plants. Following gamma irradiation, $\mathrm{M}_{1}$ plants were transferred to a greenhouse and cultivated until 28 weeks from sowing to collect $\mathrm{M}_{2}$ seeds. Data are presented as mean \pm SE of 12 biological replicates for each dose. Asterisks represent significant differences between gamma-irradiated and control plants (unpaired $t$-test: ${ }^{*} p<0.05$; $* * * p<0.001)$. 


\subsection{Chronic Gamma Irradiation Affects the Expression of Genes Involved in Trichome Development and the ROS Signaling Pathway}

To examine which genes triggered the changes in trichome density in the gammairradiated plants, the expression levels of genes involved in trichome development were analyzed by qRT-PCR. Since 100 Gy- and 200 Gy-irradiated plants presented with mild and severe phenotypes, the leaves of these plants were used for gene expression analysis. The expression levels of the $W o$ and $C y c B 2$ genes, which regulate the initiation of type I trichomes in tomato $[37,38]$, were similar between gamma-irradiated and control leaves (Figure 2A). However, the expression level of the $M Y C 1$ gene, which is essential for the initiation of type VI trichomes [39], was significantly reduced by $48-56 \%$ in $100 \mathrm{~Gy}$ - and 200 Gy-irradiated leaves, compared to that in control leaves. The expression level of the TPS5 gene, which is highly expressed in type VI trichomes and whose expression regulates the synthesis of monoterpenes [40], also decreased by $49-54 \%$ in $100 \mathrm{~Gy}$ - and 200 Gy-irradiated leaves compared to that in control leaves (Figure 2A).

A
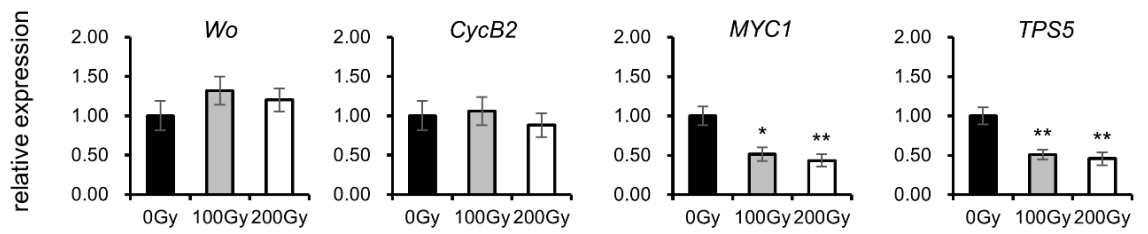

B
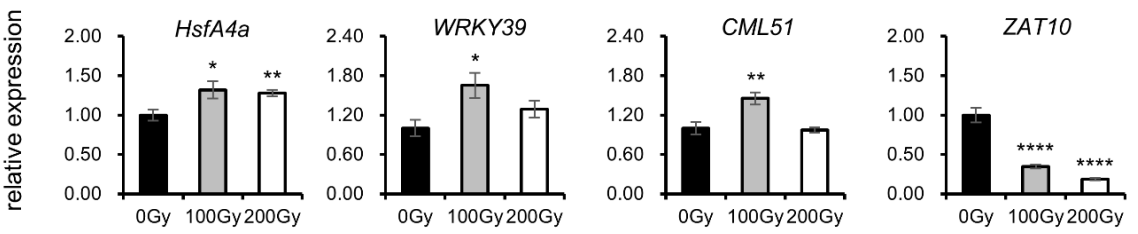

C
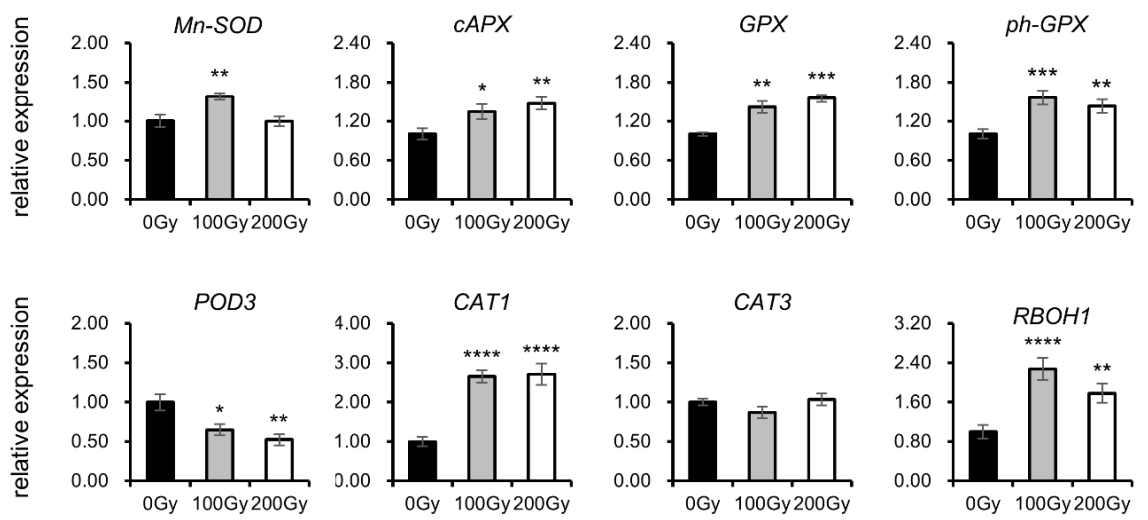

Figure 2. Expression levels of genes involved in trichome development, reactive oxygen species (ROS) signaling, and scavenging in leaves of gamma-irradiated $\mathrm{M}_{1}$ plants. Control (0 Gy) plants and gamma-irradiated plants (100 and $200 \mathrm{~Gy}$ ) were used. Gene expression levels were analyzed via quantitative real-time polymerase chain reaction (qRT-PCR) and the values were normalized to the levels in control plants. Data are presented as mean $\pm \mathrm{SE}$ of four biological replicates. Asterisks represent significant differences between control and gamma-irradiated plants (unpaired $t$-test: ${ }^{*} p<0.05$; ${ }^{* *} p<0.01$; ${ }^{* * *} p<0.001$; ${ }^{* * * *} p<0.0001$ ). (A) Genes involved in trichome development. (B) Genes related to reactive oxygen species (ROS) signaling. (C) Genes involved in ROS scavenging. 
Acute and chronic gamma irradiation is known to alter the expression of several ROS signaling-related genes, such as heat shock factors (HSFs), WRKYs, calcium binding proteins, and zinc transporters (ZATs) in Arabidopsis [36]. Therefore, we analyzed the expression levels of genes related to the ROS signaling pathway. The expression level of HsfA4a increased to $33 \%$ and $29 \%$ in leaves irradiated with 100 Gy and 200 Gy, respectively, compared with that in the control leaves. WRKY39 and CML51 showed a $65 \%$ and $45 \%$ increase in $100 \mathrm{~Gy}$-irradiated leaves, respectively, compared to the findings observed in control leaves. However, the expression level of ZAT10 decreased to $65-81 \%$ in $100 \mathrm{~Gy}-$ and 200 Gy-irradiated leaves compared to that in control leaves (Figure 2B). ROS signaling promotes the expression of genes encoding antioxidant enzymes, such as superoxide dismutase (SOD), ascorbate peroxidase (APX), glutathione peroxidase (GPX), phospholipid hydroperoxide GPX (phGPX), peroxidase (POD), and catalase (CAT) [41-43]. To investigate antioxidant-related responses to chronic gamma irradiation, the expression of the corresponding genes was analyzed. The transcript level of $M n-S O D$ increased to $32 \%$ in 100 Gy-irradiated leaves compared to that in control leaves. The expression levels of $c A P X$, GPX, ph-GPX, and CAT1 increased to 34-165\% in 100 Gy-irradiated leaves and $42-171 \%$ in 200 Gy-irradiated leaves compared with those in control leaves. However, the expression levels of POD3 decreased to 35\% and 48\% in leaves irradiated with 100 and $200 \mathrm{~Gy}$, respectively. The expression levels of $C A T 3$ were similar between the gamma-irradiated and control leaves. In the case of respiratory burst oxidase homologue1 (RBOH1), which encodes NADPH oxidase [44], the transcript level was upregulated to $125 \%$ and $73 \%$ in 100 Gy- and 200 Gy-irradiated leaves compared with that in control leaves (Figure 2C).

3.3. $M_{2}$ Plants Obtained from Gamma-Irradiated $M_{1}$ Plants Exhibit Normal Trichome Density and Fruit Shape but Demonstrate Reduced Leaf Size and Seed Number

To investigate whether the phenotypes observed in the gamma-irradiated $\mathrm{M}_{1}$ plants were maintained in the next generation, $\mathrm{M}_{2}$ seeds were germinated and cultivated in a greenhouse. Then, the phenotypes of 7-week-old tomato plants were examined. First, the leaf length of $\mathrm{M}_{2}$ plants obtained from $50 \mathrm{~Gy}$ - and $100 \mathrm{~Gy}$-irradiated $\mathrm{M}_{1}$ (hereafter referred to as $50-\mathrm{Gy}_{2}$ plants and 100-Gy $\mathrm{M}_{2}$ plants) was similar to that of $\mathrm{M}_{2}$ plants obtained from control ( 0 Gy) $M_{1}$ plants (hereafter referred to as control $\mathrm{M}_{2}$ plants). The leaf length of 150- and 200-Gy $\mathrm{M}_{2}$ plants was reduced by $9-18 \%$ compared with that of control $\mathrm{M}_{2}$ plants (Figure $3 \mathrm{~A}$ ). The density of type I and type VI trichomes on the leaves of the gammairradiated $\mathrm{M}_{2}$ plants was similar to that of the control $\mathrm{M}_{2}$ plants (Figure 3B-D). The fruit of the gamma-irradiated $\mathrm{M}_{2}$ plants exhibited a normal shape, similar to the fruit of control $\mathrm{M}_{2}$ plants (Figure 3E). However, the seed production of gamma-irradiated $\mathrm{M}_{2}$ plants was similar to that of gamma-irradiated $\mathrm{M}_{1}$ plants. The number of $\mathrm{M}_{3}$ seeds obtained from 50-Gy $\mathrm{M}_{2}$ plants decreased to $19 \%$; however, this was not significantly different from that of control $\mathrm{M}_{2}$ plants. The number of $\mathrm{M}_{3}$ seeds obtained from 100-, 150-, and 200-Gy $\mathrm{M}_{2}$ plants was significantly reduced to $42-51 \%$ compared with that of control $\mathrm{M}_{2}$ plants (Figure $3 \mathrm{~F}$ ). These results indicated that the changes in phenotype (leaf length and seed number) were maintained in $\mathrm{M}_{2}$ plants obtained from gamma-irradiated $\mathrm{M}_{1}$ plants. 
A

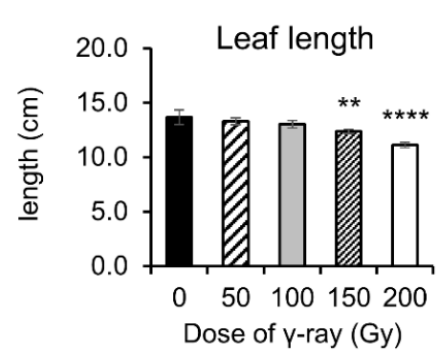

B

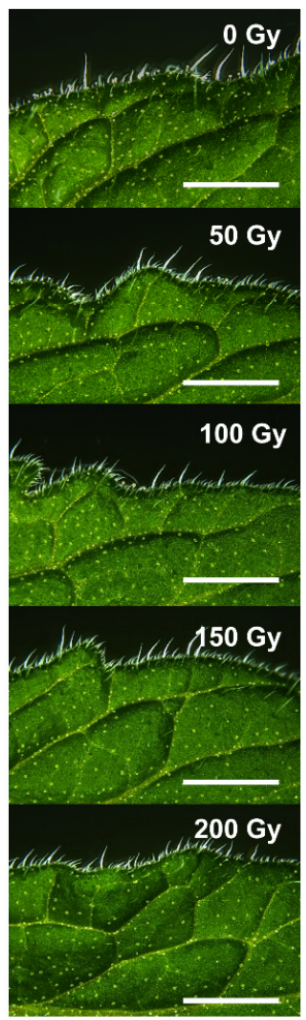

C

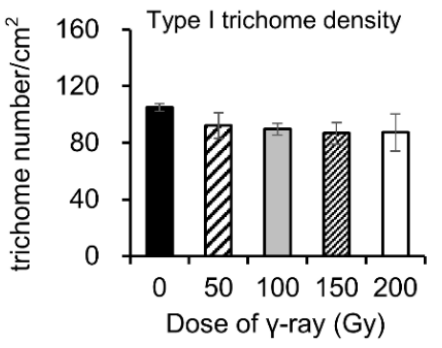

D

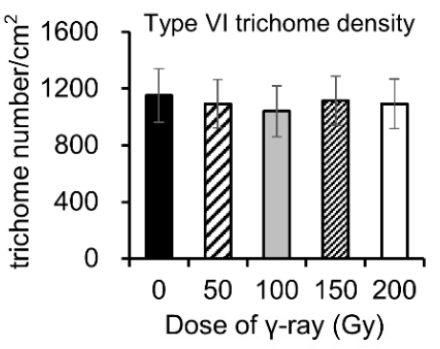

E

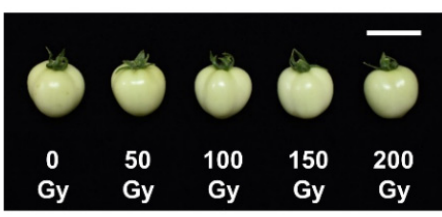

$\mathbf{F}$

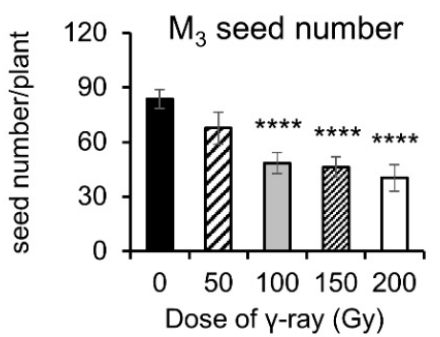

Figure 3. Effect of chronic gamma irradiation on growth and development of tomato $\mathrm{M}_{2}$ plants. $\mathrm{M}_{2}$ seeds harvested from the control (0 Gy) $\mathrm{M}_{1}$ and $\mathrm{M}_{1}$ plants irradiated with 50, 100, 150, or $200 \mathrm{~Gy}$ of gamma rays were germinated, grown for 7 weeks, and used. (A) Leaf length of control and gamma-irradiated plants. The length from the center of the plant to the edge of the largest terminal leaflet was measured. Data are presented as mean $\pm \mathrm{SE}$ of 12 biological replicates for each dose. Asterisks represent significant differences between control and gamma-irradiated plants (unpaired $t$-test: $\left.{ }^{* *} p<0.01 ; * * * * p<0.0001\right)$. (B) Dissecting micrographs of the adaxial leaf surfaces of the control and gamma-irradiated plants. Scale bars represent $2 \mathrm{~mm}$. (C,D) Density of type I (C) and VI (D) trichomes on the adaxial leaves of control and gamma-irradiated plants. Data are presented as mean \pm SE of six biological replicates for each dose. (E) Shape of mature green fruit in the control and gamma-irradiated plants. Scale bar indicates $2 \mathrm{~cm}$. (F) $\mathrm{M}_{3}$ seed numbers of the control and gamma-irradiated $M_{2}$ plants. $M_{2}$ plants were grown for 28 weeks in a greenhouse to harvest the $\mathrm{M}_{3}$ seeds. Data are presented as mean $\pm \mathrm{SE}$ of 12 biological replicates for each dose. Asterisks represent significant differences between the control and gamma-irradiated plants (unpaired $t$-test: $* * * * 00.0001)$.

\subsection{Expression Levels of ZAT10, Mn-SOD, POD3, and RBOH1 Are Altered in $M_{2}$ Plants}

The expression levels of the Wo and CycB2 genes in 100- and 200-Gy $\mathrm{M}_{2}$ plants were similar to those observed in control $\mathrm{M}_{2}$ plants (Figure $4 \mathrm{~A}$ ). The expression levels of $\mathrm{MYC1}$ and TPS5 genes were also similar between 100- and 200-Gy $\mathrm{M}_{2}$ plants and control $\mathrm{M}_{2}$ plants 
(Figure 4A). These results were consistent with the similar density of type I and VI trichomes between the gamma-irradiated $\mathrm{M}_{2}$ plants and control $\mathrm{M}_{2}$ plants (Figure 3B). In general, the expression of genes related to ROS signaling and scavenging was not different between the gamma-irradiated $\mathrm{M}_{2}$ and control $\mathrm{M}_{2}$ plants (Figure $4 \mathrm{~B}, \mathrm{C}$ ). However, the transcript level of ZAT10 was downregulated to $28 \%$ in 100- and 200-Gy $\mathrm{M}_{2}$ plants compared with that in control $\mathrm{M}_{2}$ plants. In contrast, $M n$-SOD expression was upregulated to $76 \%$ in $100-\mathrm{Gy} \mathrm{M}_{2}$ plants. The expression level of POD3 was reduced to 33-31\% in 100- and 200-Gy $\mathrm{M}_{2}$ plants, respectively, compared with that in control $\mathrm{M}_{2}$ plants. Moreover, the expression level of $R B O H 1$ was highly upregulated to $102-59 \%$ in $100-$ and $200-\mathrm{Gy}_{2}$ plants compared with that in control $\mathrm{M}_{2}$ plants (Figure 4B,C). The changes in the expression of ZAT10, Mn-SOD, $P O D 3$, and $R B O H 1$ were examined at least twice. These results indicated that the effects of chronic gamma irradiation on $\mathrm{M}_{1}$ plants were transmitted to the next generation.

A
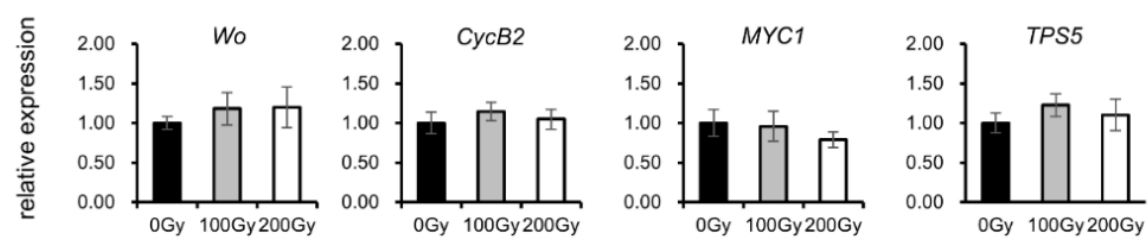

B
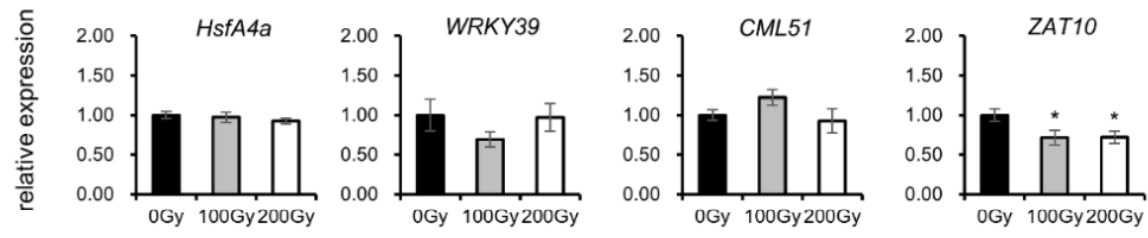

C
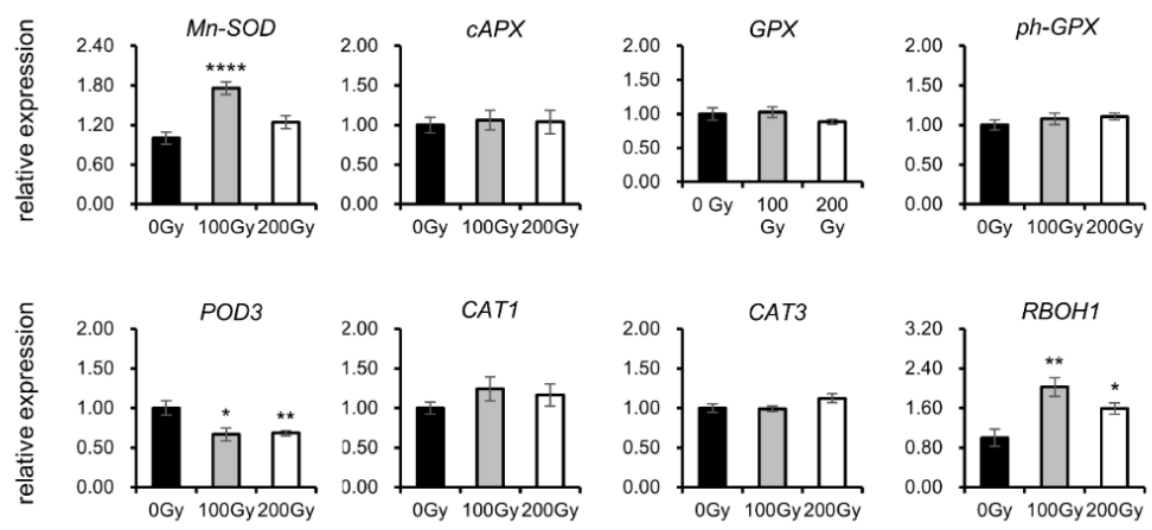

Figure 4. Expression levels of genes involved in trichome development, reactive oxygen species (ROS) signaling, and scavenging in leaves of gamma-irradiated $\mathrm{M}_{2}$ plants. $\mathrm{M}_{2}$ seeds harvested from the control (0 Gy) $\mathrm{M}_{1}$ plants and the $\mathrm{M}_{1}$ plants irradiated with 100 or $200 \mathrm{~Gy}$ of gamma rays were germinated, cultivated for 7 weeks, and assessed. Gene expression levels were analyzed via qRT-PCR, and the values were normalized to the levels in control plants. Data are presented as mean $\pm \mathrm{SE}$ of six biological replicates. Asterisks represent significant differences between gamma-irradiated and control plants (unpaired $t$-test: ${ }^{*} p<0.05 ;{ }^{* *} p<0.01 ; * * * * p<0.0001$ ). (A) Genes involved in trichome development. (B) Genes related to ROS signaling. (C) Genes involved in ROS scavenging. 


\section{5. $M_{2}$ Mutant Generation from Chronically Gamma-Irradiated $M_{1}$ Plants}

In general, seeds are subjected to irradiation with acute gamma rays to facilitate the establishment of a mutant population $[45,46]$. To examine the feasibility of using chronically gamma-irradiated tomato plants in the establishment of a mutant population, $184 \mathrm{M}_{2}$ seeds (40 seeds from $0 \mathrm{~Gy}-50 \mathrm{~Gy}-, 100 \mathrm{~Gy}-$, and $150 \mathrm{~Gy}$-irradiated $\mathrm{M}_{1}$ lines, and 24 seeds from 200 Gy-irradiated $M_{1}$ lines) were sown. Phenotypes of $M_{2}$ lines were screened to identify mutants. Three mutants with different phenotypes were observed compared to the control plants. The mutant-1 (m-1) plants presented with chlorotic leaves compared to control plants that presented with green leaves (Figure 5A). Compared with the control fruit, which exhibited a round shape, the mutant- $2(\mathrm{~m}-2)$ plants presented with elongated fruit with abnormal tip regions developed from the stigma of the flowers (Figure $5 \mathrm{~B}$ ). The mutant-3 (m-3) plants presented with bush leaves and floral buds, which did not undergo development into flowers (Figure $5 \mathrm{C}$ ). The findings in the $\mathrm{M}_{2}$ plants implied that chronic gamma irradiation induced mutations that were transmitted to the next generation; thus, chronic gamma irradiation could be considered for the establishment of mutant populations in tomato.
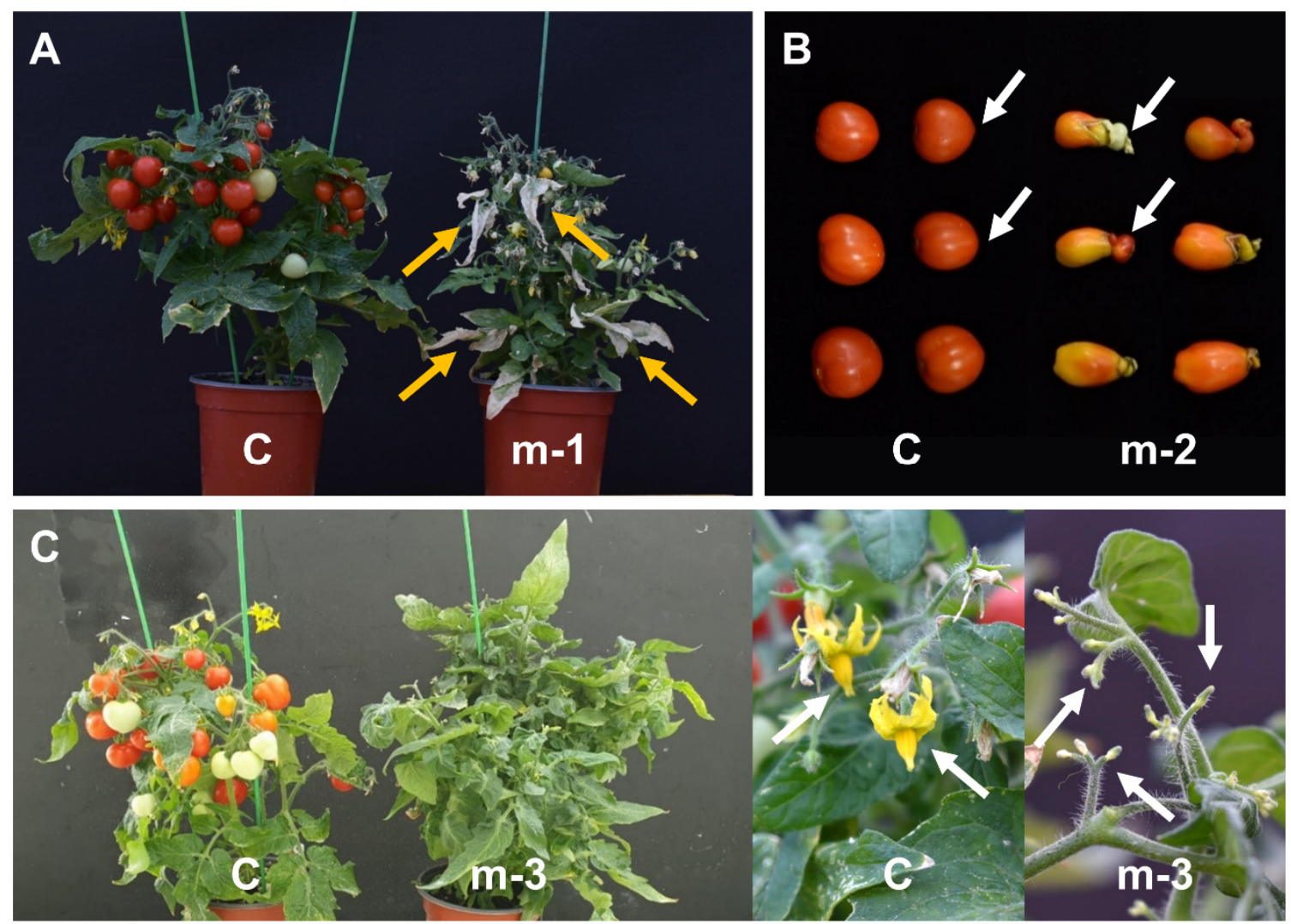

Figure 5. Various phenotypes of mutant $\mathrm{M}_{2}$ plants. Mutants ( $\mathrm{m}-1, \mathrm{~m}-2$, and $\mathrm{m}-3$ ) with different phenotypes compared with control (C) plants are shown. (A) An m-1 mutant with chlorotic leaves (indicated by arrows). (B) An m-2 mutant with abnormal fruit shape. Arrows indicate the tip regions developed from the stigma of the flowers. (C) m-3 mutant with bushy leaves and floral buds, which did not develop into flowers. Arrows indicate flowers and floral buds in WT and m-3 plants, respectively.

\section{Discussion}

The physiological and mutagenic effects of acute radiation on plants have been widely studied, but relatively limited data are available on the effects of chronic irradiation on plants [20]. As the biological effects of radiation can be continuously monitored during various developmental stages, investigation of the effects of chronic irradiation will facilitate a more multifaceted understanding of plant response to radiation. This understanding 
is necessary for predicting plant development and inheritance in radiation-exposed terrestrial areas or non-terrestrial space environments where cosmic radiation exists, and for the application of chronic irradiation to mutation breeding [47]. Although physiological characteristics or gene expression patterns in response to chronic irradiation have been analyzed [3,7,11], integrative studies combining both research areas are limited. Additionally, there has been limited research on the analysis of inheritance of characteristics under uncontrolled irradiation conditions $[48,49]$. Therefore, we investigated the changes in biological characteristics induced in tomato via subjection to chronic irradiation, and the inheritance of such characteristics, to facilitate a comprehensive understanding of radiation biology in plants.

We used the dwarf tomato cultivar 'Micro-Tom', which exhibits a short life cycle (70-90 days) [30], therefore, conducting irradiation for a period of 4 weeks could cover multiple developmental stages, including vegetative growth, flowering, and fruit set, and helped elucidate the changes occurring at each stage. The biological effects investigated during and after chronic irradiation were categorized into the following three groups: deleterious effects on plant growth and reproduction (reduced leaf length and seed set); developmental and morphological effects (changes in trichome density and fruit shape); and alteration of the expression patterns of genes related to antioxidant activity and trichome development (Table 1). The reduction in leaf length and seed set might be attributable to both the physiological and genetic effects of radiation. Irradiation at low doses (1-5 Gy irradiation) during vegetative stages stimulates growth in several plant species such as pepper, pea, and wheat [50-52]. However, irradiation at high doses (>50 Gy irradiation) during vegetative stages usually leads to deleterious physiological effects, including infliction of damage to cellular components, by inducing ROS production [47], by diminishing the ATP/ADP ratio presumably by impairing the photosynthesis system [53], and by lowering the content of indoleacetic acid (IAA) via reduction of IAA synthesis [54] and acceleration of its degradation [55]. These effects may be related to reduced leaf length and seed set observed in our study, considering that IAA positively regulates plant growth [56] and a substantial amount of energy is required for gametophyte development $[57,58]$. Regarding genetic effects, radiation often induces chromosomal aberrations such as chromosome breaks, deletions, chromatid exchanges, and chromatin bridges [59]. Chromosomal abnormalities can hamper the normal segregation of chromosomes during mitosis and meiosis [60-62], which may cause retarded growth and reduced fertility, respectively. Additionally, the accumulation of various DNA mutations in the haploid genome of gametophytes may affect the function of gametophyte development-related genes. In our analysis, a reduction in seed set was detected following subjection to irradiation at high doses. Hase et al. $[17,63]$ showed that the frequency of DNA mutations, including single-substitutions, small InDels, and DNA structural variation, increased when irradiation was applied at higher doses.

Table 1. Summary of biological changes caused by chronic irradiation of the tomato cultivar 'Micro-Tom'.

\begin{tabular}{|c|c|c|}
\hline Categories of Biological Change & Changes in $\mathbf{M}_{1}$ Plants & $\begin{array}{l}\text { Transmission to the Next } \\
\text { Generation }\left(\mathrm{M}_{2}\right)\end{array}$ \\
\hline \multirow{2}{*}{ Impaired growth and reproduction } & Reduced leaf length & Partially transmitted \\
\hline & Reduced seed set & Partially transmitted \\
\hline \multirow{2}{*}{ Developmental and morphological changes } & Reduced trichome density & Not transmitted \\
\hline & Increased length-to-width ratio of fruits & Not transmitted \\
\hline \multirow{2}{*}{ Alteration of gene expression pattern } & $\begin{array}{l}\text { Downregulation of expression of } \\
\text { trichome development genes }\end{array}$ & Not transmitted \\
\hline & $\begin{array}{l}\text { Upregulation of expression of ROS } \\
\text { response-related genes }\end{array}$ & $\begin{array}{l}\text { Partially transmitted (four out of the } \\
\text { twelve genes tested) }\end{array}$ \\
\hline
\end{tabular}


Trichomes are specialized cells that undergo differentiation from the epidermis of plants and play an essential role in conferring protection to plants against various biotic and abiotic stresses [64-66]. We detected a decrease in the density of type VI trichomes on leaves when gamma rays were used for chronic irradiation at a dose of 100-200 Gy for 4 weeks. This decrease might be attributable to a decrease in the expression of the MYC1 gene, which is involved in the initiation of type VI trichomes through the jasmonic acid (JA) signaling pathway [39]. Since salicylic acid (SA) signaling is triggered by ROS accumulation [67], and as there exists an antagonistic crosstalk between SA and JA [68], the reduction in type VI trichomes could be explained by the continuous SA signaling induced by ROS. Goh et al. [36] showed that trichome formation was promoted in Arabidopsis seedlings irradiated with a gamma-ray dose of $200 \mathrm{~Gy}$ for both $1 \mathrm{~h}$ and 1 week. The reason for the inconsistent trichome phenotypes between Arabidopsis and tomato is unknown. However, the difference may be attributed to the sensitivity of plant species to radiation, duration of radiation, or dose rate. For example, different dose rates may affect gene expression to a variable extent.

Comparative analysis between groups of Arabidopsis plants subjected to irradiation with ${ }^{137} \mathrm{Cs}$ at $1 \mathrm{~Gy}$ for a period of 14 days (chronic irradiation) and a single pulse (acute irradiation) showed that the two groups shared $<10 \%$ differentially expressed genes [69]. The dose rate of chronic irradiation reported by Goh et al. [36] was $1.2 \mathrm{~Gy} / \mathrm{h}$, while it was markedly lower in our study [0.15 Gy/h (total $100 \mathrm{~Gy}$ ) to $0.30 \mathrm{~Gy} / \mathrm{h}$ (total $200 \mathrm{~Gy}$ )]. We also showed that gamma-irradiated (50, 100, and $150 \mathrm{~Gy}$ ) tomato lines could develop fruits with a higher length-to-width ratio. Rodríguez et al. [70] classified tomato fruit shape into eight groups and found that the allele distribution of four major genes was strongly related to fruit morphology. The expression of two genes, SUN and OVATE, regulated the elongated shape, and the expression of other genes, namely FASCIATED and LOCULE NUMBER, modulated fruit locule number and the flat shape [70]. The unique peanutshaped morphology of fruit derived from irradiated tomato plants did not match any of the eight groups classified by Rodríguez et al. [70]. This suggests that changes in the expression level of unidentified fruit shape-related genes may be responsible for the abnormal fruit shape observed in our study. The tomato fruit with unique characteristics found in our study could be used as a novel research material for investigating the relationship between environmental stress, gene expression, and fruit morphology.

Regarding gene expression, the expression levels of HsfA4a, WRKY39, and CML51, which are upstream transcription factors that exhibit responses to ROS [71-73], increased in $\mathrm{M}_{1}$ plants. This was similar to the findings reported in Arabidopsis [74]. However, the expression of ZAT10 decreased after subjection to chronic gamma irradiation. In Arabidopsis, the overexpression of ZAT10 conferred resistance to osmotic stress and salinity; however, resistance to the same stresses was also detected when ZAT10 was subjected to knockout [75]. The expression of ZAT10 increased in Arabidopsis following subjection to acute gamma irradiation [74], however, in tomato, the expression decreased following subjection to chronic gamma irradiation in this study. This result implies that the method of controlling gene expression to counter stress attributable to irradiation may differ according to the plant species or dose rate. The expression of the antioxidant gene RBOH1, which is induced by photo-oxidative stress [44], increased at doses of 100 and $200 \mathrm{~Gy}$. Interestingly, among the genes exhibiting an upregulated expression, expression levels were higher in the 100-Gy group than those in the 200-Gy group. It was presumed that a dose of $200 \mathrm{~Gy}$ exceeded the limit below which the defense mechanism could effectively mount responses against ROS in tomato. In contrast, the transcription of POD3 decreased at doses of 100 and 200 Gy. Similarly, Goh et al. [36] showed that POD activity decreased during 3 weeks of subjection to chronic gamma irradiation in Arabidopsis seedlings. When tomato leaves were subjected to drought stress for a period of 4 weeks, the formation of a new isoform of POD3 was observed [76]. Further studies are warranted to determine the effect of chronic gamma irradiation on POD3. Expression levels of a considerable proportion of the tested tomato genes (Mn-SOD, cAPX, GPX, phGPX, and CAT1) encoding ROS-scavenging 
enzymes were also upregulated after subjection to chronic gamma irradiation, as observed for their Arabidopsis orthologs [74].

Our results showed that the transmissibility of biological changes caused by chronic irradiation depended on the type of effect (Table 1). Changes in trichome density and fruit shape were not inherited to the next generation, suggesting that they were caused by changes in gene expression or protein function in response to irradiation, without the occurrence of inheritable genetic modifications. This conclusion was supported by the absence of a significant difference in the expression levels of trichome development-related genes between progenies from gamma-irradiated and wild-type tomatoes. In contrast, there was partial inheritance of reductions in leaf length and seed set and changes in the expression of several antioxidant genes in the progenies, indicating the involvement of inheritable genetic modifications. The inheritance of large structural variation in DNA can be a potential mechanism because chromosomal aberrations may result in the retardation of growth and reduction in fertility in the irradiated plants. However, this was unlikely to be the main mechanism because the majority of DNA structural variation in $\mathrm{M}_{1}$ plants was lost, presumably during gametophyte development [14]. Hase et al. [17] demonstrated that the progeny of Arabidopsis plants obtained following treatment with chronic gamma irradiation for five successive generations harbored a high ratio of small DNA mutations (e.g., single-substitutions and small InDels) compared to a considerable structural variation. They also found that the frequency of DNA mutations was higher following subjection to chronic gamma irradiation (168 homozygous mutation events per plant on average with 916 Gy irradiation) than acute gamma irradiation (16.3 homozygous mutation events per plant on average with 1000 Gy irradiation). Therefore, the additive effects of the accumulated small DNA mutations might partly contribute to the deleterious phenotypes observed in the $\mathrm{M}_{1}$ and $\mathrm{M}_{2}$ generations.

In addition to DNA mutations, irradiation has been shown to affect epigenetic modifications by increasing the expression of epigenetic regulators (MET1, CMT3, and SUVH5) in Arabidopsis subjected to irradiation with X-rays [77]; furthermore, modifications pertaining to hypermethylated DNA sequences in Pinus sylvestris trees exposed to radiation after the Chernobyl accident [78] and hypomethylated DNA sequences in rice subjection to irradiation with gamma rays [3] have also been observed. Sidler et al. [75] hypothesized that epigenetic changes (hypermethylation in this case) following radiation exposure might constitute an adaptive response of plants to prevent genome instability and reshuffling. The inheritance of epigenetic changes in plants has been reported in various biological areas [79-81]. As changes in the expression pattern of a few ROS-related genes (ZAT10, $M n-S O D, P O D 3$, and $R B O H 1$ ) were found to be inherited to the next generation, it might be inferred that the epigenetic effects of irradiation could affect the expression of radiationresponsive genes and, in turn, might cause the inheritance of certain phenotypic changes and gene expression patterns. Boratyński et al. [48] showed that the progenies of carrots subjected to chronic irradiation around Chernobyl showed higher resistance to irradiation. The upregulation of expression of ROS-related genes in our $\mathrm{M}_{2}$ lines may be related to this type of adaptation to radiation. Further genome-wide investigation into the changes in gene expression patterns and epigenetic modifications in $\mathrm{M}_{1}$ and $\mathrm{M}_{2}$ generations is necessary to clarify the mechanism underlying the inheritance of phenotypic and genetic changes.

Large mutant populations with mutant phenotype databases have been developed via subjection to acute gamma irradiation and EMS treatment of 'Micro-Tom' [30,82,83]. Since Hase et al. [17] have shown that chronic gamma irradiation is more effective for the accumulation of DNA mutations with less radiation-associated damage than acute irradiation, and have suggested that further development of mutant populations can be attempted by applying chronic irradiation. The present study showed that phenotypic mutants could be obtained in the $\mathrm{M}_{2}$ generation, as expected. The optimal irradiation dose for mutagenesis should be determined for the development and establishment of large mutant populations. For 'Micro-Tom', Matsukura et al. [80] established a mutant population following subjection to acute gamma irradiation at a dose of $300 \mathrm{~Gy}$, which 
reduced the germination rate by $30 \%$. In our previous study conducted on acutely gammairradiated 'Micro-Tom', the survival rate significantly decrease from $300 \mathrm{~Gy}$ [46]. Thus, a dose of 300 Gy was considered as the shoulder dose that could help generate the highest number of mutants per sown $\mathrm{M}_{1}$ seed [16]. The number of seeds per fruit in plants subjected to irradiation with a dose of $300 \mathrm{~Gy}$ was $84 \%$ of that in the original plants (data not shown). At instances where the seed set rate in the present study was considered, the significance of the biological effects exerted by acute gamma irradiation at a dose of $300 \mathrm{~Gy}$ seemed similar to that observed with chronic gamma irradiation at a dose ranging from 50-100 Gy. This result was consistent with that reported by Hase et al. [63], who showed that Arabidopsis seeds were six times more tolerant to carbon beams than the tolerance exhibited by seedlings. However, when the transgenerational effect on the seed set is considered, chronic irradiation at a dose of $100 \mathrm{~Gy}$ may hamper the maintenance of mutant populations as a significant decrease in the seed set could be detected in the $\mathrm{M}_{2}$ generation. Therefore, we suggest the application of a dose of $50 \mathrm{~Gy}$ as an optimal dose for mutant population establishment using chronic gamma irradiation in 'Micro-Tom'.

\section{Conclusions}

We investigated the biological changes and their inheritance in 'Micro-Tom' plants following subjection to chronic gamma irradiation. The biological effects detected in the $\mathrm{M}_{1}$ generation included reduction in leaf length and seed set, changes in trichome density and fruit shape, and alteration of the expression pattern of genes involved in trichome development and antioxidant response. Few changes in phenotype and gene expression patterns were also detected in the $\mathrm{M}_{2}$ generation, suggesting the existence of transgenerational inheritance of biological changes caused by irradiation. Meanwhile, the optimal dose for chronic gamma irradiation for the development of a 'Micro-Tom' mutant population was determined to be $50 \mathrm{~Gy}$, considering the biological effects in both the $\mathrm{M}_{1}$ and $\mathrm{M}_{2}$ generations. Based on our findings, we suggest that this study will provide valuable information for understanding plant response to radiation and will provide a resource for executing the application of chronic irradiation for conducting functional genomics studies and breeding in tomatoes.

Supplementary Materials: The following are available online at https:/ / www.mdpi.com/article/ 10.3390 / agronomy11081638/s1, Table S1. Primers used for qRT-PCR. Figure S1. Schematic diagram of tomato seedling treatment with chronic gamma irradiation. Figure S2. Dissecting micrograph of the adaxial leaf surface derived from 7-week-old 'Micro-Tom' plants.

Author Contributions: J.-H.K. and J.-B.K. designed the experiments. S.-M.K., Y.D.J. and J.-I.C. performed the experiments. S.-M.K., Y.D.J., J.-B.K. and J.-H.K. analyzed the data. S.-M.K., Y.D.J. and J.-H.K. wrote the first draft of the manuscript. J.-H.K. prepared the final draft and was responsible for the correspondence. All authors have read and agreed to the published version of the manuscript.

Funding: This research was supported by a grant from the New Breeding Technologies Development Program (Project No. PJ01478502) from the Rural Development Administration, Korea, and grants from the Nuclear R\&D Program of the Ministry of Science and ICT (MSIT), and the research program of KAERI, Korea.

Data Availability Statement: The data presented in this study are available in Supplementary Materials.

Conflicts of Interest: The authors declare no conflict of interest.

\section{References}

1. Shu, Q.-Y.; Forster, B.P.; Nakagawa, H.; Nakagawa, H. Plant Mutation Breeding and Biotechnology; CABI: Wallingford, UK, 2012.

2. Hidema, J.; Yamoto, M.; Kumagai, T.; Hase, Y.; Sakamoto, A.; Tanaka, A. Biological effects of carbon ion on rice (Oryza sativa L.). JAERI Rev. 2003, 33, 85-87.

3. Choi, H.I.; Han, S.M.; Jo, Y.D.; Hong, M.J.; Kim, S.H.; Kim, J.B. Effects of acute and chronic gamma irradiation on the cell biology and physiology of rice plants. Plants 2021, 10, 439. [CrossRef] [PubMed]

4. Nagata, T.; Todoriki, S.; Hayashi, T.; Shibata, Y.; Mori, M.; Kanegae, H.; Kikuchi, S. $\gamma$-radiation induces leaf trichome formation in Arabidopsis. Plant Physiol. 1999, 120, 113-120. [CrossRef] [PubMed] 
5. Kim, D.Y.; Hong, M.J.; Park, C.S.; Seo, Y.W. The effects of chronic radiation of gamma ray on protein expression and oxidative stress in Brachypodium distachyon. Int. J. Radiat. Biol. 2015, 91, 407-419. [CrossRef]

6. Hayashi, T.; Aoki, S. Effect of irradiation on the carbohydrate metabolism responsible for sucrose accumulation in potatoes. J. Agric. Food Chem. 1985, 33, 14-17. [CrossRef]

7. Hong, M.J.; Kim, J.B.; Yoon, Y.H.; Kim, S.H.; Ahn, J.W.; Jeong, I.Y.; Kang, S.Y.; Seo, Y.W.; Kim, D.S. The effects of chronic gamma irradiation on oxidative stress response and the expression of anthocyanin biosynthesis-related genes in wheat (Triticum aestivum). Int. J. Radiat. Biol. 2014, 90, 1218-1228. [CrossRef]

8. Wi, S.G.; Chung, B.Y.; Kim, J.-H.; Baek, M.-H.; Yang, D.H.; Lee, J.-W.; Kim, J.-S. Ultrastructural changes of cell organelles in Arabidopsis stems after gamma irradation. J. Plant Biol. 2005, 48, 195-200. [CrossRef]

9. Belfield, E.J.; Gan, X.; Mithani, A.; Brown, C.; Jiang, C.; Franklin, K.; Alvey, E.; Wibowo, A.; Jung, M.; Bailey, K.; et al. Genome-wide analysis of mutations in mutant lineages selected following fast-neutron irradiation mutagenesis of Arabidopsis thaliana. Genome Res. 2012, 22, 1306-1315. [CrossRef] [PubMed]

10. Lee, S.I.; Park, J.W.; Kwon, S.J.; Jo, Y.D.; Hong, M.J.; Kim, J.B.; Choi, H.I. Epigenetic variation induced by gamma rays, DNA methyltransferase inhibitors, and their combination in rice. Plants 2020, 9, 1088. [CrossRef]

11. Kim, J.B.; Kim, S.H.; Ha, B.K.; Kang, S.Y.; Jang, C.S.; Seo, Y.W.; Kim, D.S. Differentially expressed genes in response to gammairradiation during the vegetative stage in Arabidopsis thaliana. Mol. Biol. Rep. 2014, 41, 2229-2241. [CrossRef]

12. Tanaka, A.; Shikazono, N.; Hase, Y. Studies on biological effects of ion beams on lethality, molecular nature of mutation, mutation rate, and spectrum of mutation phenotype for mutation breeding in higher plants. J. Radiat. Res. 2010, 51, 223-233. [CrossRef] [PubMed]

13. Wi, S.G.; Chung, B.Y.; Kim, J.S.; Kim, J.H.; Baek, M.H.; Lee, J.W.; Kim, Y.S. Effects of gamma irradiation on morphological changes and biological responses in plants. Micron 2007, 38, 553-564. [CrossRef] [PubMed]

14. Naito, K.; Kusaba, M.; Shikazono, N.; Takano, T.; Tanaka, A.; Tanisaka, T.; Nishimura, M. Transmissible and nontransmissible mutations induced by irradiating Arabidopsis thaliana pollen with $\gamma$-rays and carbon ions. Genetics 2005, 169, 881-889. [CrossRef] [PubMed]

15. Jo, Y.D.; Kim, J.-B. Frequency and spectrum of radiation-induced mutations revealed by whole-genome sequencing analyses of plants. Quantum Beam Sci. 2019, 3, 7. [CrossRef]

16. Yamaguchi, H.; Hase, Y.; Tanaka, A.; Shikazono, N.; Degi, K.; Shimizu, A.; Morishita, T. Mutagenic effects of ion beam irradiation on rice. Breed. Sci. 2009, 59, 169-177. [CrossRef]

17. Hase, Y.; Satoh, K.; Seito, H.; Oono, Y. Genetic consequences of acute/chronic gamma and carbon ion irradiation of Arabidopsis thaliana. Front. Plant Sci. 2020, 11, 336. [CrossRef] [PubMed]

18. Kazama, Y.; Ishii, K.; Hirano, T.; Wakana, T.; Yamada, M.; Ohbu, S.; Abe, T. Different mutational function of low- and high-linear energy transfer heavy-ion irradiation demonstrated by whole-genome resequencing of Arabidopsis mutants. Plant J. 2017, 92, 1020-1030. [CrossRef] [PubMed]

19. Li, G.; Jain, R.; Chern, M.; Pham, N.T.; Martin, J.A.; Wei, T.; Schackwitz, W.S.; Lipzen, A.M.; Duong, P.Q.; Jones, K.C.; et al. The sequences of 1504 mutants in the model rice variety Kitaake facilitate rapid functional genomic studies. Plant Cell 2017, 29, 1218-1231. [CrossRef]

20. Caplin, N.; Willey, N. Ionizing radiation, higher plants, and radioprotection: From acute high doses to chronic low doses. Front. Plant Sci. 2018, 9, 847. [CrossRef] [PubMed]

21. Cheng, Z.; Lin, J.; Lin, T.; Xu, M.; Huang, Z.; Yang, Z.; Huang, X.; Zheng, J. Genome-wide analysis of radiation-induced mutations in rice (Oryza sativa L. ssp. indica). Mol. Biosyst. 2014, 10, 795-805. [CrossRef] [PubMed]

22. Azhar, M.; Ahsanulkhaliqin, A.W. Gamma greenhouse: A chronic facility for crops improvement and agrobiotechnology. In AIP Conference Proceedings; American Institute of Physics: College Park, MD, USA, 2014; Volume 1584, pp. 32-37.

23. Kang, S.-Y.; Kim, J.-B.; Lee, G.-J.; Kim, D.S. Gamma Phytotron: A New Chronic Gamma Irradiation Facility. 2010. Available online: https:/ / inis.iaea.org/search/search.aspx?orig_q=RN:42080083 (accessed on 14 August 2021).

24. Kawara, K. Introduction of a Gamma Field in Japan; Elsevier: Amsterdam, The Netherlands, 1963.

25. Sanada, T.; Kotobuki, K.; Nishida, T.; Fujita, H.; Ikeda, F. A new Japanese pear cultivar 'Gold Nijisseiki', resistant mutant to black spot disease of Japanese pear. Jpn. J. Breed. 1993, 43, 455-461. [CrossRef]

26. Nagatomi, S.; Miyahira, E.; Degi, K. Combined Effect of Gamma Irradiation Methods and In Vitro Explant Sources on Mutation Induction of Flower Color in Chrysanthemum morifoliun Ramat. Gamma Field Symposia. 1997, pp. 51-69. Available online: https:/ /inis.iaea.org/search/search.aspx?orig_q=RN:30030357 (accessed on 14 August 2021).

27. FAOSTAT. 2021. Available online: http:/ / www.fao.org/faostat/en/\#data (accessed on 8 June 2021).

28. Menda, N.; Semel, Y.; Peled, D.; Eshed, Y.; Zamir, D. In silico screening of a saturated mutation library of tomato. Plant J. 2004, 38, 861-872. [CrossRef]

29. Minoia, S.; Petrozza, A.; D'Onofrio, O.; Piron, F.; Mosca, G.; Sozio, G.; Cellini, F.; Bendahmane, A.; Carriero, F. A new mutant genetic resource for tomato crop improvement by TILLING technology. BMC Res. Notes 2010, 3, 69. [CrossRef] [PubMed]

30. Saito, T.; Ariizumi, T.; Okabe, Y.; Asamizu, E.; Hiwasa-Tanase, K.; Fukuda, N.; Mizoguchi, T.; Yamazaki, Y.; Aoki, K.; Ezura, H. TOMATOMA: A novel tomato mutant database distributing Micro-Tom mutant collections. Plant Cell Physiol. 2011, 52, $283-296$. [CrossRef] [PubMed] 
31. Shirasawa, K.; Hirakawa, H.; Nunome, T.; Tabata, S.; Isobe, S. Genome-wide survey of artificial mutations induced by ethyl methanesulfonate and gamma rays in tomato. Plant Biotechnol. J. 2016, 14, 51-60. [CrossRef]

32. De Nettancourt, D.D.; Contant, R.B. Comparative study of the effects of chronic gamma irradiation on Lycopersicum esculentum Mill. and L. pimpinellifolium Dunal. Radiat. Bot. 1996, 6, 545-556. [CrossRef]

33. Sidrak, G.H.; Suess, A. Effects of low doses of gamma radiation on the growth and yield of two varieties of tomato. Radiat. Bot. 1973, 13, 309-314. [CrossRef]

34. Jeong, N.-R.; Kim, H.; Hwang, I.-T.; Howe, G.A.; Kang, J.-H. Genetic analysis of the tomato inquieta mutant links the Arp2/3 complex to trichome development. J. Plant Biol. 2017, 60, 582-592. [CrossRef]

35. Celik, O.; Atak, C.; Suludere, Z. Response of soybean plants to gamma radiation: Biochemical analyses and expression patterns of trichome development. South Cross J. 2014, 7, 382.

36. Goh, E.J.; Kim, J.B.; Kim, W.J.; Ha, B.K.; Kim, S.H.; Kang, S.Y.; Seo, Y.W.; Kim, D.S. Physiological changes and anti-oxidative responses of Arabidopsis plants after acute and chronic $\gamma$-irradiation. Radiat. Environ. Biophys. 2014, 53, 677-693. [CrossRef] [PubMed]

37. Yang, C.; Li, H.; Zhang, J.; Luo, Z.; Gong, P.; Zhang, C.; Li, J.; Wang, T.; Zhang, Y.; Lu, Y.; et al. A regulatory gene induces trichome formation and embryo lethality in tomato. Proc. Natl. Acad. Sci. USA 2011, 108, 11836-11841. [CrossRef] [PubMed]

38. Gao, S.; Gao, Y.; Xiong, C.; Yu, G.; Chang, J.; Yang, Q.; Yang, C.; Ye, Z. The tomato B-type cyclin gene, SlCycB2, plays key roles in reproductive organ development, trichome initiation, terpenoids biosynthesis and Prodenia litura defense. Plant Sci. 2017, 262, 103-114. [CrossRef]

39. Xu, J.; van Herwijnen, Z.O.; Dräger, D.B.; Sui, C.; Haring, M.A.; Schuurink, R.C. SIMYC1 regulates type VI glandular trichome formation and terpene biosynthesis in tomato glandular cells. Plant Cell 2018, 30, 988-3005. [CrossRef] [PubMed]

40. Spyropoulou, E.A.; Haring, M.A.; Schuurink, R.C. RNA sequencing on Solanum Lycopersicum trichomes identifies transcription factors that activate terpene synthase promoters. BMC Genom. 2014, 15, 402. [CrossRef] [PubMed]

41. Feng, K.; Yu, J.; Cheng, Y.; Ruan, M.; Wang, R.; Ye, Q.; Zhou, G.; Li, Z.; Yao, Z.; Yang, Y.; et al. The SOD gene family in tomato: Identification, phylogenetic relationships, and expression patterns. Front. Plant Sci. 2016, 7, 1279. [CrossRef] [PubMed]

42. Martinez, V.; Nieves-Cordones, M.; Lopez-Delacalle, M.; Rodenas, R.; Mestre, T.C.; Garcia-Sanchez, F.; Rubio, F.; Nortes, P.A.; Mittler, R.; Rivero, R.M. Tolerance to stress combination in tomato plants: New insights in the protective role of melatonin. Molecules 2018, 23, 535. [CrossRef]

43. Yao, G.F.; Wei, Z.Z.; Li, T.T.; Tang, J.; Huang, Z.Q.; Yang, F.; Li, Y.H.; Han, Z.; Hu, F.; Hu, L.Y.; et al. Modulation of enhanced antioxidant activity by hydrogen sulfide antagonization of ethylene in tomato fruit ripening. J. Agric. Food Chem. 2018, 66, 10380-10387. [CrossRef] [PubMed]

44. Zhou, J.; Xia, X.J.; Zhou, Y.H.; Shi, K.; Chen, Z.; Yu, J.Q. RBOH1-dependent H2O2 production and subsequent activation of MPK1/2 play an important role in acclimation-induced cross-tolerance in tomato. J. Exp. Bot. 2014, 65, 595-607. [CrossRef]

45. Beyaz, R.; Yildiz, M. The use of gamma irradiation in plant mutation breeding. In Plant Engineering, 1st ed.; Snježana, J., Ed.; In Tech: Rijeka, Croatia, 2017; pp. 33-46.

46. Chun, J.-I.; Kim, H.; Jo, Y.D.; Kim, J.-B.; Kang, J.-H. Development of a mutant population of micro-tom tomato using gammairradiation. Plant Breed. Biotech. 2020, 8, 307-315. [CrossRef]

47. Gudkov, S.V.; Grinberg, M.A.; Sukhov, V.; Vodeneev, V. Effect of ionizing radiation on physiological and molecular processes in plants. J. Environ. Radioact. 2019, 202, 8-24. [CrossRef]

48. Boratyński, Z.; Arias, J.M.; Garcia, C.; Mappes, T.; Mousseau, T.A.; Møller, A.P.; Pajares, A.J.M.; Piwczyński, M.; Tukalenko, E. Ionizing radiation from Chernobyl affects development of wild carrot plants. Sci. Rep. 2016, 6, 1-8. [CrossRef] [PubMed]

49. Fedotov, I.S.; Kal'chenko, V.A.; Igoninna, E.V.; Rubanovich, A.V. Radiation and genetic consequences of ionizing irradiation on population of Pinus sylvestris L. within the zone of the Chernobyl NPP. Radiats. Biol. Radioecol. 2006, 46, 268-278. [PubMed]

50. Kim, J.-H.; Baek, M.-H.; Chung, B.Y.; Wi, S.G.; Kim, J.-S. Alterations in the photosynthetic pigments and antioxidant machineries of red pepper (Capsicum annuum L.) seedlings from gamma-irradiated seeds. J. Plant Biol. 2004, 47, 314-321. [CrossRef]

51. Kumar, P.; Sharma, V.; Atmaram, C.K.; Singh, B. Regulated partitioning of fixed carbon (14 C), sodium (Na+), potassium (K+) and glycine betaine determined salinity stress tolerance of gamma irradiated pigeon pea [Cajanus cajan (L.) Millsp]. Environ. Sci. Pollut. Res. Int. 2017, 24, 7285-7297. [CrossRef] [PubMed]

52. Singh, B.; Ahuja, S.; Singhal, R.K.; Venu Babu, P.V. Effect of gamma radiation on wheat plant growth due to impact on gas exchange characteristics and mineral nutrient uptake and utilization. J. Radioanal. Nucl. Chem. 2013, 298, 249-257. [CrossRef]

53. Vasilenko, A.; Zhadko, S.; Sidorenko, P. Alteration in lipid peroxidation in plant cells after accelerated ion irradiation. In Biological Effects and Physics of Solar and Galactic Cosmic Radiation; Springer: Boston, MA, USA, 1993; pp. 155-159.

54. Fortunati, A.; Tassone, P.; Damasso, M.; Migliaccio, F. Neutron irradiation affects the expression of genes involved in the response to auxin, senescence and oxidative stress in Arabidopsis. Plant Signal. Behav. 2010, 5, 959-967. [CrossRef] [PubMed]

55. Parups, E.V. Involvement of free radicals in the oxidative degradation of indole-3-acetic acid. Can. J. Biochem. 1969, 47, 220-224. [CrossRef] [PubMed]

56. Tanimoto, E. Regulation of root growth by plant hormones-Roles for auxin and gibberellin. Crit. Rev. Plant Sci. 2005, 24, 249-265. [CrossRef]

57. Lee, S.J.; Warmke, H.E. Organelle size and number in fertile and T-cytoplasmic male-sterile corn. Am. J. Bot. 1979, 66, 141-148. [CrossRef] 
58. Tadege, M.; Kuhlemeier, C. Aerobic fermentation during tobacco pollen development. Plant Mol. Biol. 1997, 35, 343-354. [CrossRef]

59. De Micco, V.; Arena, C.; Pignalosa, D.; Durante, M. Effects of sparsely and densely ionizing radiation on plants. Radiat. Environ. Biophys. 2011, 50, 1-19. [CrossRef] [PubMed]

60. Mukherjee, S.; Datta, A.K. Mitotic and meiotic consequences of gamma irradiations on dry seeds of Nigella sativa L. (black cumin). J. Plant Dev. Sci. 2011, 3, 233-238.

61. Natarajan, A. Chromosome aberrations: Plants to human and feulgen to FISH. Curr. Sci. 2005, 89, 335-340.

62. Vochita, G.; Focea-Ghioc, R.; Creanga, D. Direct versus indirect radiation action in irradiated vegetal embryos. Cent. Eur. J. Biol. 2014, 9, 993-1003. [CrossRef]

63. Hase, Y.; Satoh, K.; Kitamura, S.; Oono, Y. Physiological status of plant tissue affects the frequency and types of mutations induced by carbon-ion irradiation in Arabidopsis. Sci. Rep. 2018, 8, 1-10. [CrossRef] [PubMed]

64. Kang, J.H.; Liu, G.; Shi, F.; Jones, A.D.; Beaudry, R.M.; Howe, G.A. The tomato odorless-2 mutant is defective in trichome-based production of diverse specialized metabolites and broad-spectrum resistance to insect herbivores. Plant Physiol. 2010, 154, 262-272. [CrossRef]

65. Yuan, Y.; Xu, X.; Luo, Y.; Gong, Z.; Hu, X.; Wu, M.; Liu, Y.; Yan, F.; Zhang, X.; Zhang, W.; et al. R2R3 MYB-dependent auxin signalling regulates trichome formation, and increased trichome density confers spider mite tolerance on tomato. Plant Biotechnol. J. 2021, 19, 138-152. [CrossRef] [PubMed]

66. Zhang, Y.; Song, H.; Wang, X.; Zhou, X.; Zhang, K.; Chen, X.; Liu, J.; Han, J.; Wang, A. The roles of different types of trichomes in tomato resistance to cold, drought, whiteflies, and Botrytis. Agronomy 2020, 10, 411. [CrossRef]

67. Herrera-Vásquez, A.; Salinas, P.; Holuigue, L. Salicylic acid and reactive oxygen species interplay in the transcriptional control of defense genes expression. Front. Plant Sci. 2015, 6, 171. [CrossRef] [PubMed]

68. Robert-Seilaniantz, A.; Grant, M.; Jones, J.D. Hormone crosstalk in plant disease and defense: More than just jasmonate-salicylate antagonism. Annu. Rev. Phytopathol. 2011, 49, 317-343. [CrossRef] [PubMed]

69. Kovalchuk, I.; Molinier, J.; Yao, Y.; Arkhipov, A.; Kovalchuk, O. Transcriptome analysis reveals fundamental differences in plant response to acute and chronic exposure to ionizing radiation. Mutat. Res. 2007, 624, 101-113. [CrossRef] [PubMed]

70. Rodríguez, G.R.; Muños, S.; Anderson, C.; Sim, S.C.; Michel, A.; Causse, M.; Gardener, B.B.M.; Francis, D.; van der Knaap, E. Distribution of SUN, OVATE, LC, and FAS in the tomato germplasm and the relationship to fruit shape diversity. Plant Physiol. 2011, 156, 275-285. [CrossRef] [PubMed]

71. Bai, Y.; Sunarti, S.; Kissoudis, C.; Visser, R.G.F.; Van Der Linden, C.G. The role of tomato WRKY genes in plant responses to combined abiotic and biotic stresses. Front. Plant Sci. 2018, 9, 801. [CrossRef]

72. Munir, S.; Khan, M.R.G.; Song, J.; Munir, S.; Zhang, Y.; Ye, Z.; Wang, T. Genome-wide identification, characterization and expression analysis of calmodulin-like (CML) proteins in tomato (Solanum lycopersicum). Plant Physiol. Biochem. 2016, 102, 167-179. [CrossRef]

73. Zhou, J.; Xu, X.C.; Cao, J.J.; Yin, L.L.; Xia, X.J.; Shi, K.; Zhou, Y.H.; Yu, J.Q. Heat shock factor HsfA1a is essential for R gene-mediated nematode resistance and triggers $\mathrm{H}_{2} \mathrm{O}_{2}$ Production. Plant Physiol. 2018, 176, 2456-2471. [CrossRef]

74. Kim, D.S.; Kim, J.B.; Goh, E.J.; Kim, W.J.; Kim, S.H.; Seo, Y.W.; Jang, C.S.; Kang, S.Y. Antioxidant response of Arabidopsis plants to gamma irradiation: Genome-wide expression profiling of the ROS scavenging and signal transduction pathways. J. Plant Physiol. 2011, 168, 1960-1971. [CrossRef]

75. Mittler, R.; Kim, Y.; Song, L.; Coutu, J.; Coutu, A.; Ciftci-Yilmaz, S.; Lee, H.; Stevenson, B.; Zhu, J.K. Gain- and loss-of-function mutations in Zat10 enhance the tolerance of plants to abiotic stress. FEBS Lett. 2006, 580, 6537-6542. [CrossRef] [PubMed]

76. Hasanagić, D.; Koleška, I.; Kojić, D.; Vlaisavljević, S.; Janjić, N.; Kukavica, B. Long-term drought effects on tomato leaves: Anatomical, gas exchange and antioxidant modifications. Acta Physiol. Plant. 2020, 42, 1-14. [CrossRef]

77. Sidler, C.; Li, D.; Kovalchuk, O.; Kovalchuk, I. Development-dependent expression of DNA repair genes and epigenetic regulators in Arabidopsis plants exposed to ionizing radiation. Radiat. Res. 2015, 183, 219-232. [CrossRef] [PubMed]

78. Kovalchuk, O.; Burke, P.; Arkhipov, A.; Kuchma, N.; James, S.J.; Kovalchuk, I.; Pogribny, I. Genome hypermethylation in Pinus silvestris of Chernobyl-A mechanism for radiation adaptation? Mutat. Res. 2003, 529, 13-20. [CrossRef]

79. Gallusci, P.; Dai, Z.; Génard, M.; Gauffretau, A.; Leblanc-Fournier, N.; Richard-Molard, C.; Vile, D.; Brunel-Muguet, S. Epigenetics for plant improvement: Current knowledge and modeling avenues. Trends Plant Sci. 2017, 22, 610-623. [CrossRef]

80. Grossniklaus, U.; Kelly, W.G.; Kelly, B.; Ferguson-Smith, A.C.; Pembrey, M.; Lindquist, S. Transgenerational epigenetic inheritance: How important is it? Nat. Rev. Genet. 2013, 14, 228-235. [CrossRef]

81. Kinoshita, T.; Seki, M. Epigenetic memory for stress response and adaptation in plants. Plant Cell Physiol. 2014, 55, 1859-1863. [CrossRef] [PubMed]

82. Matsukura, C.; Aoki, K.; Fukuda, N.; Mizoguchi, T.; Asamizu, E.; Saito, T.; Shibata, D.; Ezura, H. Comprehensive resources for tomato functional genomics based on the miniature model tomato Micro-Tom. Curr. Genom. 2008, 9, 436-443. [CrossRef]

83. Watanabe, S.; Mizoguchi, T.; Aoki, K.; Kubo, Y.; Mori, H.; Imanishi, S.; Yamazaki, Y.; Shibata, D.; Ezura, H. Ethylmethanesulfonate (EMS) mutagenesis of Solanum lycopersicum cv. Micro-Tom for large-scale mutant screens. Plant Biotechnol. 2007, $24,33-38$. [CrossRef] 